\title{
Mulher-casa, mulher-faca
}

Priscilla Menezes de Faria ${ }^{1}$

Resumo: Historicamente, feminino está relacionado à incompletude e incompletude à falta. Nesse ensaio, entretanto, incompletude é apresentada como condição necessária à criação e o feminino como uma via de acesso ao pensamento poético. As séries Femme-couteau e Femme-maison de Louise Bourgeois são apresentadas a partir da relação dialética entre cortar/rachar/romper e acolher/gestar/criar.

Palavras-chave: Feminino, Louise Bourgeois, hospitalidade, pensamento poético.

\section{House-woman, knife-woman}

Abstract: Historically, feminine has been related to incompleteness and incompleteness to lack. In this essay, however, incompleteness is presented as the necessary condition for creation and the feminine as a way of access to poetic thought. The series Femme-couteau and Femme-maison by Louise Bourgeois are presented through the dialectic relation between cut/split/break and host/generate /create.

Key-words: Feminine, Louise Bourgeois, hospitality, poetic thought.

Perpetuou-se longamente no pensamento ocidental a noção de que feminino equivale à incompletude. Essa ideia, em geral, se baseia no deslocamento de uma percepção anatômica para um pressuposto metafísico, como ocorre no pensamento aristotélico. Dentre as inúmeras diferenças entre os corpos, o filósofo grego se ateve

\footnotetext{
1 Priscilla Menezes é artista e pesquisadora. Trabalha, especialmente, com as linguagens do desenho e do texto. Autora do livro Erro tácito (2017, Editora Patuá). Realizou a exposição individual "Partenogênese", em 2018, na Galeria Gustavo Schnoor. Graduada em Licenciatura em Artes Plásticas pela UDESC, mestre e doutora em Artes Visuais pela UERJ.
} 
às diferenças genitais e marcou ontologicamente o feminino a partir da ausência do falo. Assim, associou o feminino à incompletude, pois não foi capaz de pensar a diferença como um elemento si, considerando-a antes em termos hierárquicos - a natureza masculina como plena e a natureza feminina como insuficiente, malformada (ARISTOTELES apud PINTO, 2010, p. 26). O filósofo associou feminino à privação e, com isso, justificou o fato de considerar as mulheres essencialmente inaptas à vida política. Afirmava que, por serem faltosas, eram cognitivamente inferiores, incapazes de elaboração filosófica e de autoridade moral. Definiu, com isto, que a aptidão natural das mulheres estava circunscrita à vida doméstica sob a tutela dos homens. Em suma, lhes atribuiu um montante reduzido de cidadania (PINTO, 2010, p. 26).

Isso indica que Aristóteles não apenas naturalizou uma associação entre anatomia e metafísica, como faltou em compreender que vagina não é um pênis ausente, e sim um órgão inteiro cuja a própria completude inclui a abertura: uma forma plena que contém o vão. No pensamento aristotélico, completude e abertura são mutuamente excludentes, pois só considera completo aquilo que se fecha em si. Exemplo disso é a sua teoria acerca da reprodução humana na qual considerava advir inteiramente do homem a partícula formadora de um novo ser; enquanto, à mulher, relegava o papel de mera incubadora. Ou seja, só considerava haver capacidade política e criativa no corpo que pensava ser inteiro.

Análoga à noção de que o corpo feminino é incompleto é a ideia de que seria portador de um vazio temerário. Etienne Trillat (1991) afirma remontar à alta Antiguidade o pensamento segundo o qual o útero é considerado como um organismo vivo, um animal dotado de certa autonomia. 0 autor afirma que já no antigo Egito havia a ideia de que o útero poderia migrar no interior do corpo feminino e, com isso, causar as mais diversas perturbações. Essa concepção perpetuou-se longamente e comparece inclusive na obra de Hipócrates, considerado o pai da medicina ocidental. No tomo VII de suas Obras Completas, o médico redige 250 páginas acerca das doenças das mulheres e entre elas descreve a sufocação da matriz, condição que causaria o fenômeno do útero errante. Hipócrates descreve: 


\begin{abstract}
Esta afecção sobrevém sobretudo às mulheres que não têm relações sexuais e às mulheres de uma certa idade, mais do que às jovens; com efeito, sua matriz é mais leve. Eis como isso ocorre: a mulher, tendo os vasos mais vazios que de costume e estando mais cansada, a matriz ressecada pela fadiga se desloca, visto que ela está vazia e leve; a vacuidade do ventre faz com que haja lugar para que ela se desloque (HIPÓCRATES apud TRILLAT, 1991, p. 21).
\end{abstract}

Afirmava ainda que, ao se deslocar, o útero acabava se fixando sobre os outros órgãos, desregulando os seus funcionamentos. Ou seja, apresentava o útero errante como um mal a ser atentamente combatido. Para tal, sugeria um simples tratamento: o casamento, único dispositivo que possibilitaria o coito e a gravidez capazes de aplacar a vacuidade. Platão, contemporâneo de Hipócrates, corroborou com suas teorias e as difundiu, como o fez no diálogo Timeu, no qual não apenas reforçou a teoria do ventre errante como evidenciou a associação entre o útero e animalidade. No pensamento platônico, o útero é apresentado como um animal sem alma que, caso não estivesse gerando uma vida, vagaria pelo corpo feminino provocando o adoecimento. Afirma Platão:

\begin{abstract}
Na mulher, o que se chama de matriz ou útero é como um ser vivo, possuído do desejo de fazer crianças. Quando durante muito tempo e apesar da estação favorável a matriz permanece estéril, ela se irrita perigosamente; ela se agita em todos os sentidos pelo corpo, obstrui as passagens do ar, impede a inspiração, mete o corpo, assim, nas piores angústias e lhe ocasiona outras doenças de todas as espécies (PLATÃO apud TRILLAT, 1991, p. 23).
\end{abstract}

É importante pontuar que essa associação entre útero e animalidade consiste menos no resultado de um pensamento ingênuo e mais em uma questão biopolítica. A respeito disso, Trillat afirma que "essa ideia de um pequeno animal voraz, ávido, passeador, aparece como insólita, para não dizer anacrônica, num conjunto que se quer o produto de uma observação objetiva, liberta das crenças e das superstições" (TRILLAT, 1991, p. 18). Ou seja, tal ideia não é fruto de um equívoco desinteressado, mas corresponde a um projeto de dominação.

A biopolítica sistematiza as relações entre vida e direito e, para tanto, reconhece distinção culturalmente feita entre a vida nua ou comum (zoé) e a vida política ou politizada (bios). Enquanto bios é a vida com valor em si mesma (a vida humana), zoé é a vida considerada puramente biológica cujo destino é ser manipulada pelos dispositivos ordenadores do poder (a vida animal). Nesse sentido, a noção do útero- 
animal é uma autorização filosófica para que se impute aos direitos reprodutivos das mulheres as mais atrozes formas de dominação, como se houvesse no cerne da anatomia feminina bios uma espécie de estado de exceção zoé. Na Grécia clássica, portanto, surge a ideia de que um útero vazio é um útero perigoso, animalesco, que deveria necessariamente ser tutelado pelo masculino. Esse pensamento, a um só tempo, circunscreve o feminino à sua relação com a vacuidade e define que este espaço, quando desprovido de algo que advenha do masculino, é inferior, infame e indesejável.

A artista Louise Bourgeois tratou intensamente das relações entre mulher e espacialidade em sua obra, a partir da qual podemos encontrar elementos para refutar a noção de que a relação entre feminino e vacuidade é uma relação meramente faltosa. Nascida em 1911 em Paris, passou sua infância na periferia da capital francesa onde sua família matinha um ateliê de confecção e restauro de tapeçaria. Aos 12 anos, Louise já colaborava nos negócios da família, principalmente como desenhista. Mais tarde, chegou a ingressar na faculdade de Belas Artes, mas a abandonou precocemente obtendo sua formação em desenho, pintura, gravura e escultura em diversos ateliês da cidade de Paris, como os de Fernand Léger, Paul Colin, Roger Bissière, Othon Friesz. Em 1938, Louise Bourgeois se casou com o historiador e crítico de arte norte-americano Robert Goldwart e mudou-se para Nova York, onde viveu até falecer, no ano de 2011. Produziu uma extensa obra, composta de desenhos, gravuras, objetos, esculturas e instalações (que denominava "células"), mas sempre deixou claro em seus escritos e entrevistas que se considerava, acima de tudo, uma escultora. A respeito do trânsito entre sua formação inicial e sua prática escultórica, a artista afirma:

0 fato de eu ter uma formação em tecelagem e ter me formado escultora significa que julguei o meio da tecelagem incompatível com a arte da escultura. 0 vazio e a plenitude que são essenciais para o espaço e 0 volume da escultura não estão presentes porque existe um fundo que nunca é perfurado realmente (BOURGEOIS, 2000, p. 87).

Louise Bourgeois viveu parte fundamental de sua carreira entre as vanguardas europeias e o modernismo norte-americano, cercada pelas intensidades da industrialização e das grandes guerras mundiais. As tensões entre o progresso 
industrial e os horrores das guerras animaram diversos movimentos artísticos do século XX, que buscaram elaborar essas tensões a partir do desejo comum de rompimento. A ideia de espacialidade foi incluída nos anseios rompedores vanguardistas e cada movimento artístico pesquisou essa possibilidade a partir de suas próprias estratégias. Louise, apesar de ter estudado na França com artistas associados às vanguardas, praticou um modo de singular de radicalizar a espacialidade, investigando diversos suportes a partir de alguns métodos e questões. Um dos métodos que a artista recorre, por exemplo, é a pesquisa da espacialidade através de imagens e figuras femininas. Tal recorrência aqui será pensada a partir da hipótese de que Louise Bourgeois deflagrou e pesquisou uma espécie de qualidade espacial feminina. A artista afirmou "não me interesso pelo corpo; interesso-me pelo mecanismo" (BOURGEOIS, 2000, p. 219). Portanto, podemos falar que sua investigação acerca da espacialidade foi feita, muitas vezes, através de uma pesquisa acerca de mecanismos femininos.

Recorrem em suas obras imagens que remetem à gravidez, à lactação, ao sexo, à dilaceração, à prótese. São imagens que poderíamos agrupar ali onde há articulação entre fechamento e abertura. Essa relação se realiza por muitas vias: preenchimento, invasão, transbordamento, convivência, substituição. Em todo caso, pode-se perceber nos trabalhos de Bourgeois a ênfase no espaço como campo de negociação entre o limite individualizante e o contato com a alteridade. Um desses modos de negociação que a interessou singularmente foi a habitação. Ainda em seus escritos, quando fala de sua transição de tecelã para escultora, ela posiciona o desejo pelos modos habitáveis da forma como motivação fundamental:

Pessoalmente, tenho uma ligação de longa data com tapeçarias. Quando crianças, nós as usamos para nos esconder. Essa é uma das razões pelas quais espero que sejam tão tridimensionais - porque sinto que deveriam ser de uma tal altura e peso e tamanho que daria para você se envolver nelas. (...) Uma tenda é muito importante no meu vocabulário - uma forma de escultura tecida para ser adentrada -, uma forma de arquitetura desmontável (BOURGEOIS, 2000, p. 89).

Essa questão está bem marcada em suas figuras chamadas Femme Maison, mulheres-casa, que comparecem em momentos e linguagens diferentes no decorrer de seu trabalho. Primeiro Bourgeois realizou três pinturas, entre 1945 e 1947, nas 
quais corpos femininos tem arquiteturas domésticas no lugar do tórax e da cabeça. Esses corpos sustentam o agenciamento com as formas domésticas menos a partir da acumulação de formas (mulher + casa) e mais por uma via metamórfica (mulhercasa). Para tal, são apresentados em um estado no qual a circunscrição individualizante é lançada ao excesso ou à supressão, já que a esses corpos tanto sobram membros quanto faltam pedaços. No mesmo ano também produziu um desenho com o mesmo tema.
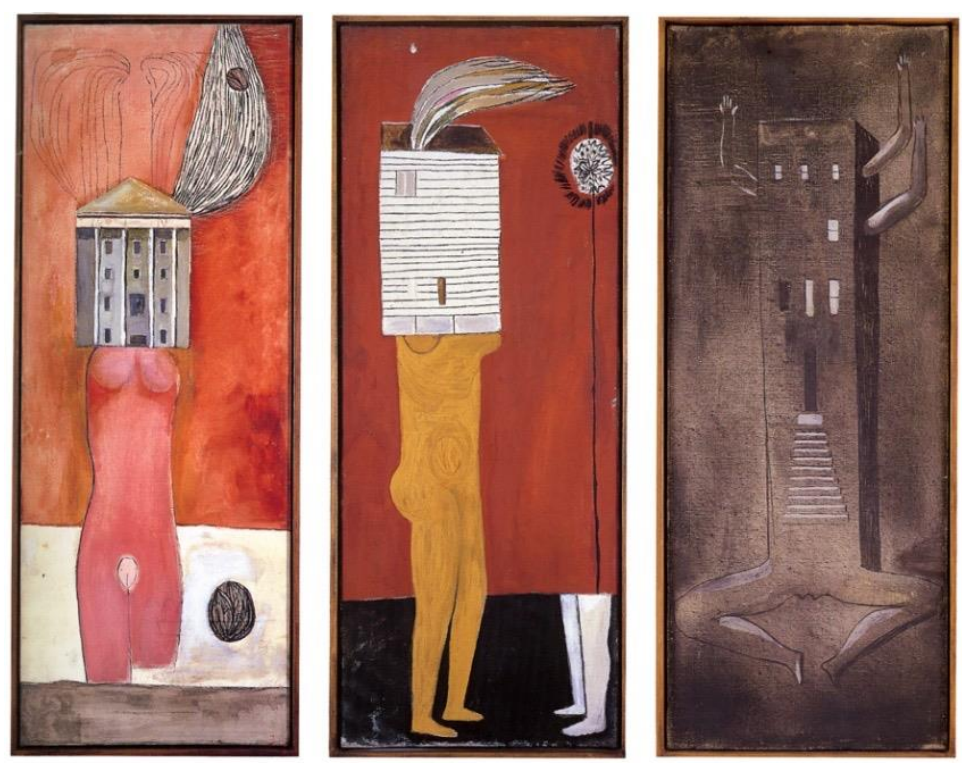

Louise Bourgeois - Série de pinturas Femme Maison -1947. Óleo sobre tela, 91,5 x 35,5 cm cada. Fonte: The Easton Foundation, NY. 


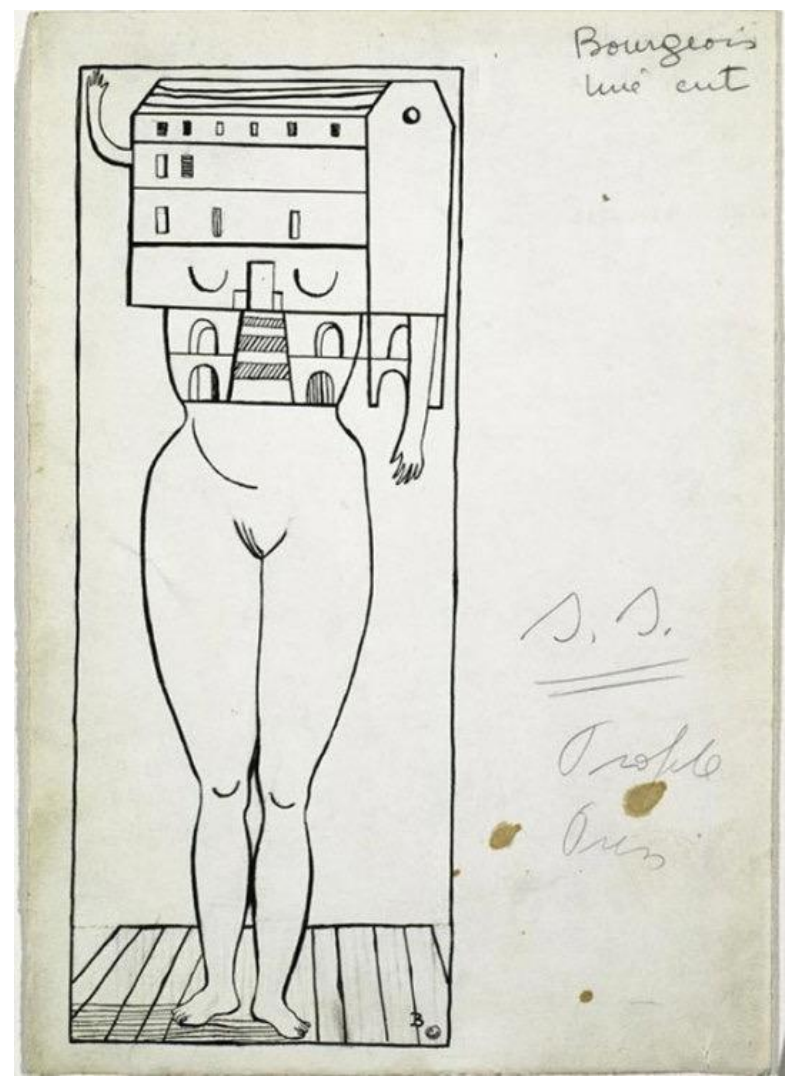

Louise Bourgeois - Femme Maison -1947. Gravura, 23.3 x $9.3 \mathrm{~cm}$.

Fonte: The Easton Foundation, NY.

Já em 1994, Bourgeois produziu uma Femme Maison de mármore, uma figura sem os braços, deitada com as pernas flexionadas e portando uma casinha no lugar onde deveria estar sua cabeça. Em 2001, realizou uma Femme Maison em tecido: um corpo quase indistinguível, ao qual faltam muitas partes e que detém uma pequena casa sobre o ventre. 


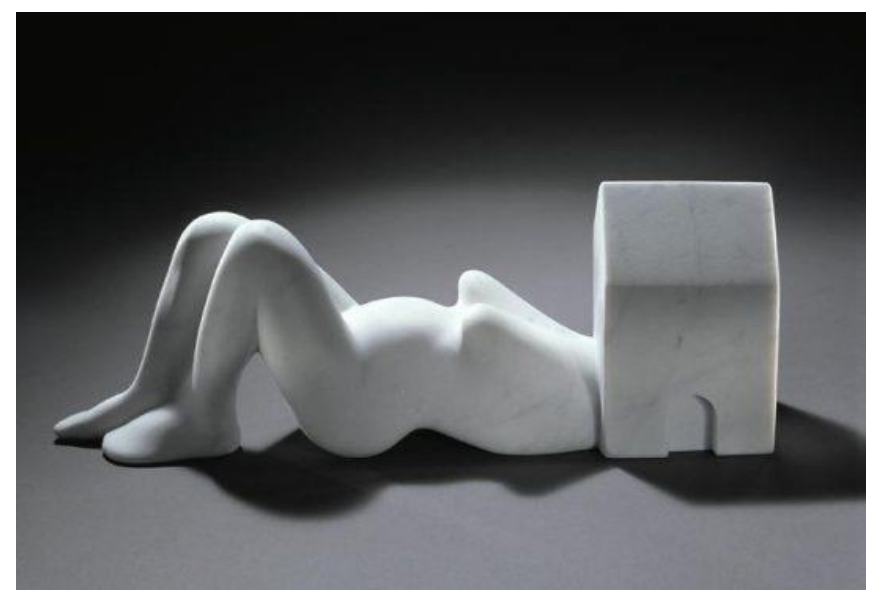

Louise Bourgeois - Femme Maison - 1994.

Mármore, 11.4 x 31.1 x 6.6 cm.Fonte: The Easton Foundation, NY.

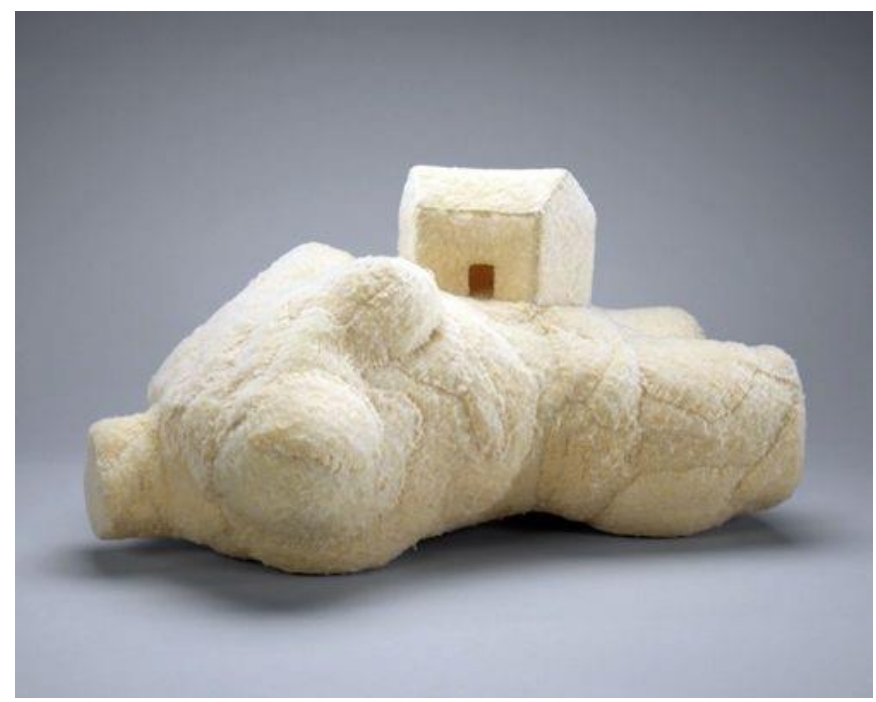

Louise Bourgeois - Femme Maison - 2001. Tecido, s.d dimensões. Fonte: The Easton Foundation, NY.

Algumas outras Femme Maison em desenho e escultura, além dessas, foram produzidas pela artista. Interessa aqui, entretanto, menos catalogar a totalidade dessa categoria em sua produção e mais compreender que o tema retornou em diversos período, a partir de diferentes linguagens, para então avançar na discussão acerca do sentido dessas obras. Algumas críticas, como as de Deborah Wye ${ }^{2}$,

${ }^{2}$ Curadora do MOMA de Nova York que organizou três importantes mostras sobre a artista nessa instituição. Informação recolhida em https://www.moma.org/audio/playlist/42/665. Acesso em: 7 abr. 2018. 
abordam o sentido das Femme Maison a partir do contexto das lutas feministas e da demanda pela desnaturalização da relação entre mulher e o trabalho doméstico. Seguindo a abordagem de Wye, essas obras explicitariam tal associação para refutála. Sustentarei aqui uma hipótese semelhante, mas a partir de um trajeto diferente no qual a afinidade entre feminino e casa não é integralmente negada, mas afirmada a partir de um ponto em que a ideia de doméstico é completamente transformada por seu agenciamento ao feminino.

Em primeiro lugar, o feminino - como potência antiessencializante - implode a possibilidade de haver uma relação essencial entre mulher e casa, mas dá pistas de que essa relação seja forjada ali onde ambas guardam relação com a abertura. Se o senso comum compreende o doméstico como em um sentido próximo a quando se adestra uma força da natureza para inseri-la na categoria de animal doméstico, aqui, a afinidade entre feminino e habitação se dá justamente no ponto em que ambas se afirmam instâncias dotadas de uma qualidade indomável.

As Femme Maison são figuras híbridas feitas de corpos femininos e formas habitáveis, nas quais persiste o fato de as partes corporais serem fragmentadas enquanto as formas domésticas se mostram completas. Aqui, entretanto, completo não significa fechado: vê-se que membros ou formas saem pelas aberturas das casinhas e, quando não há essa saída, pode-se ver uma pequena porta que cria uma fenda ou um simples recuo. Em todo caso, são abertas. Essa abertura é crucial para a construção da tensão entre individuação e alteridade que recorre no trabalho de Bourgeois, seja nas figuras humanas que se fecundam e se gestam, nos animais que metaforizam aspectos humanos, nos encontros entre modulações informes e estruturas geométricas, na indistinção entre o interno e o externo em suas células. Se frequentar é investir um espaço de uma presença exógena, a qualidade espacial que parece interessar à artista tem a ver com essa abertura à frequentação: a hospitalidade.

Derrida pensou hospitalidade como uma das potências com vocação para perturbar as instâncias asseguradoras da noção ocidental de sujeito. Fazendo uso do fato da expressão francesa chez moi significar, a um só tempo, em mim/em meu pensamento 
e em minha casa, Derrida aborda a questão do estrangeiro como o elemento que abala tanto a noção de propriedade como a noção de sujeito. No livro resultante de entrevistas com Anne Dufourmantelle acerca da hospitalidade (DERRIDA, 2003), o filósofo recupera a figura do estrangeiro nos diálogos de Platão e destaca uma passagem do diálogo O Sofista na qual o estrangeiro faz um curioso pedido: para que não o tomem erroneamente como parricida. Essa solicitação é feita ao mesmo tempo em que ataca a figura do pai, representado pelo filósofo Parmênedes, ao questionar uma premissa estruturante da filosofia parmediana: a de que a via da verdade é um caminho por onde só se avançava a partir da consideração de que o "o ser é e o nãoser não é". Ou seja, o estrangeiro ataca o pai-filósofo quando anuncia uma possibilidade divergente, estabelecendo "que o não-ser é, sob qualquer consideração, e que o ser, por sua vez, de certa maneira, não é." (DERRIDA, 2003, p. 7).Ao colocar em cena uma outra possibilidade acerca da existência afirma, por denegação, que ataca a figura do pai/filósofo. Com essa passagem, Derrida conclui que:

O estrangeiro sacode o dogmatismo ameaçador do logos paterno (...). Como se o Estrangeiro devesse começar contestando a autoridade do chefe, do pai, do chefe da família, do "dono do lugar" (...) Eis a questão temida, a hipótese revolucionária do Estrangeiro. (DERRIDA, 2003, p. 7).

Derrida localiza na filosofia clássica o que também percebe na língua francesa: a articulação entre ser e habitar. Entende que a afinidade entre essas instâncias se dá sobretudo ali onde ambas deflagram o acautelamento daquele que vem de fora. 0 estrangeiro é esse que chega para, ao mesmo tempo, fragilizar a noção de propriedade e para evidenciar zonas de intersecção entre ser e não-ser. A questão da hospitalidade se dá então em torno da pergunta: como o próprio poderia, a custo de se colocar em risco, acolher o diverso? Derrida fala de dois modos de fazê-lo: pela hospitalidade de direito e pela hospitalidade incondicional. A hospitalidade de direito tem a ver com as técnicas diplomáticas que asseguram direitos e deveres para o estrangeiro através de pactos de reciprocidade. 0 filósofo ressalta que esse modo de hospitalidade supõe, necessariamente, que o estrangeiro tenha um estatuto social e familiar. Ou seja, toda hospitalidade diplomática se baseia no fato de o estrangeiro ser dotado de nome, filiação e nacionalidade. Derrida afirma: “(...) 
não se oferece hospitalidade ao que chega anônimo e a qualquer um que não tenha nome próprio, nem patronímico, nem família, nem estatuto social, alguém que logo seria tratado não como estrangeiro, mas como mais um bárbaro" (DERRIDA, 2003, p. 23).

A hospitalidade incondicional, por sua vez, é a que rompe com as normas diplomáticas e se dá como um sim total àquele que vem. A radicalidade inerente à hospitalidade incondicional tem a ver com acolher aquele que chega sem sequer lhe perguntar o nome, ou seja, passa por implodir a relação entre acolhimento e a lógica patronímica - fundamentada sobre o nome (do pai). Derrida não coloca essa ideia como indicação de uma solução literal para as questões imigratórias, mas afirma que a hospitalidade absoluta deveria colocar a hospitalidade de direito "num movimento incessante de progresso" (DERRIDA, 2003, p. 25). Reconhece que a total abertura ao que vem de fora oferece riscos e não sugere que isso seja ignorado, mas propõe que hospitalidade de direito seja pensada junto de hospitalidade absoluta para "calcular os riscos, sim, mas sem fechar a porta ao incalculável" (DERRIDA, 2004, p. 250). É essa abertura ao incalculável que aqui nos interessa para pensarmos o tipo de abertura que sustentam as Femme Maison.

O que Derrida propõe como hospitalidade absoluta é o acolhimento daquilo que não se nomeia, ou seja, o acolhimento das potências não circunscritíveis pelo simbólico. Um vazio aberto ao inominável era o que os filósofos clássicos consideravam ser o pior dos destinos para um útero, já que este deveria estar sempre tutelado pela ordem fálica: através do controle estatal, matrimonial ou médico. Louise Bourgeois, entretanto, recupera essa afinidade com o incalculável na abertura que incute nas suas mulheres-casa: as aberturas das Femme Maison não são talhadas conforme as medidas dos preenchimentos fálicos do mundo, não são faltosas em relação a uma suposta completude fálica. Sustentam um quinhão de impreenchimento no cerne de suas próprias totalidades e, nesse sentido, se aliam à noção derridiana de hospitalidade. Diz Derrida:

(...) a hospitalidade absoluta exige que eu abra a minha casa e não apenas ofereça ao estrangeiro (provido de um nome de família, de um estatuto social de estrangeiro, etc), mas ao outro absoluto desconhecido, anônimo, 
que lhe ceda o lugar, que eu o deixe vir, que o deixe chegar (...) (DERRIDA, 2003, p. 25).

É nesse ponto em que o feminino se afirma portador de um espaço alheio à tutela fálica/simbólica/patronímica que gostaria de posicionar a ideia do útero como uma metáfora do gesto poético. Essa metáfora se ampara pela noção de que o encontro com o limite do eu é tanto condição para a hospitalidade quanto para a criação. Derrida afirma que "um ato de hospitalidade só pode ser poético" (DERRIDA, 2003, p. 4) e, reciprocamente, sustento aqui a possibilidade de todo gesto poético ser um ato de hospitalidade, no sentido de ser um gesto disponível a acolher o inominável. Elejo o útero para metaforizar essa relação justamente pela relação entre feminino e vão ser historicamente utilizada como modo de caracterizá-lo como faltoso. Ao desvelar uma qualidade potente do impreenchimento, não busco apenas atacar a misoginia estrutural como também desejo colocar em questão aquilo que pensamento ocidental evita ver no vão, recobrindo-o sem cessar de infâmia e de tutela fálica. Proponho que a metáfora uterina traga pelo menos uma resposta para essa questão ao deflagrar algo que é fatal: o fato de que a criação tem a ver com a finitude e não com a acumulação.

É interessante constatar que criação guarda pelo menos dois sentidos fortes: diz respeito ao que um sujeito cria e ao próprio evento que teria proporcionado a vida. Essa dupla compreensão se dá quando a humanidade se percebe, a um só tempo, criadora e criatura. Proponho que se possa encontrar pistas para avançar na discussão acerca da relação entre criação, feminino e finitude nos mitos da criação da espécie humana. A Bíblia conta que Deus permitiu que Adão e Eva comessem de todas as frutas do jardim do Éden, com apenas uma exceção: (Gênesis, 2,17) "Mas da árvore da ciência do bem e do mal, d'ela não comerás; porque no dia que d'ela comeres, certamente morrerás.". Como é sabido, quem rompe esta interdição divina é Eva, cuja punição por este ato foi a irreversível perda da imortalidade, o encontro inevitável com a morte.

Na mitologia grega, a primeira mulher existente foi Pandora, criada por Zeus como uma forma de punir Prometeu pelo roubo do fogo divino. Pandora foi presenteada a seu irmão, Epimeteu, o portador de uma caixa que continha todos os males 
existentes. Ao tomá-la como esposa, avisou-a que não abrisse jamais a caixa. Porém, Pandora não resistiu à curiosidade e a abriu, o que fez com que todos os males escapassem e fossem dados ao conhecimento dos homens. Nestes dois mitos, a ideia que persiste é a do feminino como potência transgressora da norma que faz emergir a consciência abrupta da finitude. Podemos considerar que o que há na caixa e no fruto é o entendimento de que o encontro com a vida é necessariamente o encontro com a morte. Entretanto, ambas as mitologias apresentam o conhecimento da finitude como fruto de uma equivocação não apenas humana, mas especificamente feminina. Como se, não fosse pela mulher, pudesse haver criação sem aniquilação. Nesse sentido, o horror ao vão - estendido como um horror ao feminino - é uma tentativa de recalcar a perda que está implicada em toda forma de criação.

Na obra de Louise Bourgeois, entretanto, criação e destruição convivem como potências dialéticas. As Femme Maison, além de acolhedoras, trazem consigo uma dimensão dilacerante. Além de possuírem formas humanas mutiladas e remendadas, a própria potência de acolhimento sustenta um sentido de risco. Derrida (2003, p. 41) apresenta a genealogia da palavra latina hostis de onde derivam tanto hóspede quanto inimigo. Para dar conta desse risco do encontro com a hostilidade implicada na prática da hospitalidade, o filósofo apresenta o conceito de hostipitalidade dando a ver que nenhuma disposição ao acolhimento do diverso é inteiramente agregadora, guardando sempre uma potência dilaceradora. Louise Bourgeois produziu ao longo de seu trabalho uma série com título análogo a das Femme Maison: as Femme Couteau. Escreve Bourgeois:

\footnotetext{
Sempre houve uma sugestionabilidade sexual em meu trabalho. Às vezes estou totalmente envolvida com formas femininas - cachos de seios como nuvens - mas muitas vezes misturo o imaginário - seios fálicos, masculino e feminino , ativo e passivo. Essa escultura de mármore - minha Femme Couteau [Mulher Faca] - personifica a polaridade das mulheres, o destrutivo e o sedutor (BOURGEOIS, 2000, p. 101).
}

Ao modo das Femme Maison, as Femme Couteau também comparecem diversos momentos de sua obra. Porém, dessa vez apenas em trabalhos escultóricos. Entre 1969 e 1970, Louise Bourgeois produziu a primeira obra que intitulou desse modo: uma escultura em mármore com dimensões aproximadas de 67 x x $12 \mathrm{~cm}$ que apresenta a fusão entre formas arredondadas e sinuosas e o talhe de uma superfície 
lisa e pontiaguda. Em 1982, produz mais duas esculturas em pedra com o mesmo título. Ambas seguem a mesma estrutura da primeira Femme Couteau: constituemse da mistura entre formas que se encaixam e se excedem a partir de um diálogo entre o esférico e o côncavo e do progressivo afunilamento de uma das faces do objeto. No ano de 2002, Bourgeois volta a produzir objetos com esse mesmo título, dessa vez feitos com tecidos e lâminas de diferentes dimensões. Suas mulheres faca são figurações de corpos incompletos, constituídos de diferentes texturas, com seus remendos e descontinuidades à mostra. Ao modo das Femme Maison, também são híbridas, se constituem da incorporação de um elemento, a priori, estranho ao orgânico. São corpos que se transformam a partir do agenciamento com o diverso e se dão, a um só tempo, incompletos e dotados da capacidade de causar a incompletude através do corte.

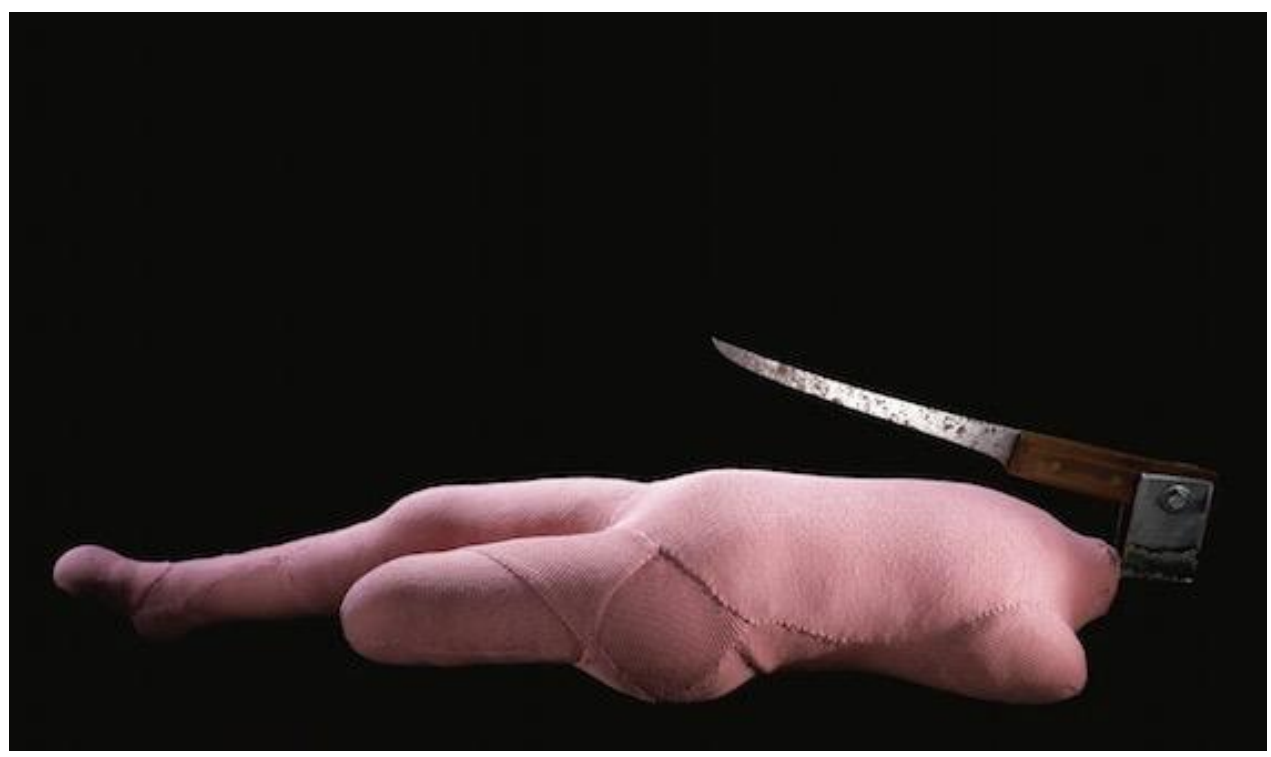

Louise Bourgeois - Femme Couteau - 2002. Tecido e objeto. s.d dimensões. Fonte : The Easton Foundation, NY.

Podemos pensar que o feminino se faz cortante quando traz notícias do estrangeirismo que há no cerne de toda identidade, ou seja, quando deflagra a alteridade que habita qualquer edifício identitário. Quando Lacan falava da alteridade feminina, não o fazia em termos de comparação (a mulher como a outra 
em relação à neutralidade masculina), mas em sentido absoluto, já que o feminino constitui algo de inominável para todos (mesmo para as mulheres). Foi nesse sentido que o psicanalista afirmou que a mulher é outra para si. Ainda recorrendo ao conceito de hospitalidade, encontramos essa analogia em Derrida quando ele diz que:

(...) para constituir o espaço de uma casa habitável e um lar, é preciso também uma abertura, uma porta e janelas, é preciso dar passagem ao estrangeiro. Não existe casa ou interioridade sem portas e janelas (DERRIDA, 2003, p. 55).

É por sustentar uma completude com abertura que o feminino tantas vezes foi relegado à dimensão do faltoso; como se, excluindo o feminino, pudesse restar um modo de existir impermeável à finitude e a alteridade. Mas o feminino mal-dito, como metáfora uterina, coloca em cena algo crucial: o fato de que o eu precisa ter limite para que o outro tenha lugar no mundo.

Não à toa, o feminino foi historicamente relacionado à loucura e que essa loucura tenha sido tantas vezes descrita através do nome de histeria. Nesse sentido, loucura seria toda alteridade a ser expurgada a fim de fazer consistirem as gramáticas falocêntricas que nada querem saber acerca da dimensão cindida da existência. Ruth Silviano Brandão resume belamente: "loucura, então, está para não-coincidência, não concordância com o narcisismo masculino" (BRANDÃO, 2004, p. 52). Dessa nãocoincidência se trata a potência destrutiva do feminino, uma potência que, ao colocar as dimensões totalizadoras em abalo, coloca em cena a possibilidade de outra forma de criação em que cabe o encontro com o inominável.

Proponho, portanto, que a qualidade especial feminina que comparece na obra de Louise Bourgeois é essa que sustenta a abertura promovedora da dialética vaziocriação. Uma dialética mal(-)dita para uma sociedade patriarcal obcecada por acumulação, que não consegue conceder com a ideia de que a criação demanda morte, de que a extrapolação demanda uma vacuidade, que a fertilidade inclui o negativo, a perda, a cisão. Em sua obra, formas grávidas, fortes, cortantes e frágeis operam de um modo em que transbordar está sempre relacionado ao ser não-toda. 0 modo como o impreenchido opera é, acima de tudo, na interrupção da rotina do 
mesmo e na abertura da passagem ao novo. Essa abertura tem mesmo algo de selvagem, pois se relaciona a isso que faz o mundo tremer: a chegada do desconhecido. Mas, se a lógica fálica considera que o desconhecido é infame e perigoso; a lógica feminina lhe dá passagem. Assim, podemos verificar que há uma proposição na obra de Bourgeois que contraria a noção aristotélica de que criação é virtude do que é impermeável: a artista a apresenta, sobretudo, como trabalho que se faz com a abertura.

\section{BIBLIOGRAFIA}

BÍBLIA. Português. A Bíblia de Jerusalém. São Paulo: Paulus, 1985.

BOURGEOIS, Louise. Destruição do pai, reconstrução do pai. São Paulo: Cosac Naify, 2000.

BRANCO, Lucia Castello; BRANDÃO, Ruth Silviano. A mulher escrita. Rio de Janeiro: Lamparina Editora, 2004.

DERRIDA, Jacques. Anne Dufourmantelle convida Jacques Derrida a falar da hospitalidade. São Paulo: Escuta, 2003.

. Papel-máquina. São Paulo: Estação Liberdade, 2004.

PINTO, Maria José Vaz. 0 que os filósofos pensam sobre as mulheres: Platão e Aristóteles. In: FERREIRA, Luísa Ribeiro Ferreira (Org). o que os filósofos pensam sobre as mulheres. São Leopoldo: Editora Unisinos, 2010.

TRILLAT, Etienne. História da histeria. São Paulo: Escuta, 1991.

Recebido em: 12/11/2018

Aprovado em: 16/11/2018 